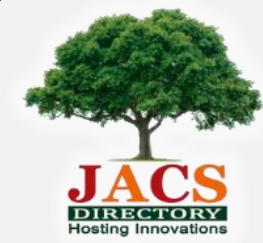

Journal of Nanoscience and Technology

\title{
A Facile Synthesis of Copper Oxide Nanorods for Photocatalytic Degradation of Organic Pollutant and Inactivation of Pathogens
}

\author{
Sathish Mohan Botsa ${ }^{1}$, Dharmasoth Ramadevi², K. Basavaiah ${ }^{1, *}$ \\ ${ }^{1}$ Department of Inorganic and Analytical Chemistry, Andhra University, Visakhapatnam - 530 003, Andhra Pradesh, India. \\ ${ }^{2} \mathrm{AU}$ College of Pharmaceutical Sciences, Andhra University, Visakhapatnam - 530 003, Andhra Pradesh, India.
}

\section{A R T I C L E D E T A I L S}

Article history:

Received 17 July 2018

Accepted 03 August 2018

Available online 07 August 2018

\section{Keywords:}

Copper Oxide Nanorods

Green Synthesis

Sonochemical Synthesis

Nitrobenzene (NB)

Photocatalysis

Antimicrobial Activity

\begin{abstract}
A B S T R A C T
In the recent years, green synthesis of nanomaterials has received a great attention to researchers in worldwide due to eco-friendly and scalable synthesis. Here, we report a green synthesis of copper oxide (CuO) nanorods via sonochemical assisted approach. The crystalline structure, band gap and morphology of as prepared CuO nanorods were investigated by UV-Vis diffuse reflectance (UV-Vis/DRS), Fourier Transform infrared spectroscopy, powder X-Ray diffraction (XRD) pattern and scanning electron microscopy (FESEM-EDX). The bandgap of as prepared $\mathrm{CuO}$ nanorods was found to be $2.0 \mathrm{eV}$, which is fall in the visible region of solar spectrum. FTIR demonstrated that there is strong interaction between $\mathrm{Cu}$ and oxygen in prepared $\mathrm{CuO}$. XRD results reveal the formation of phase pure and crystalline $\mathrm{CUO}$. FESEM images clearly show the rod like morphology of $\mathrm{CuO}$ and the presence of elemental copper and oxygen in EDX, confirms the formation of $\mathrm{CuO}$. The photocatalytic degradation activity of CuO nanorods was examined against a model dye pollutant, nitrobenzene (NB) under visible light irradiation. $\mathrm{CuO}$ nanorods were effectively degraded the NB under visible light irradiation. CuO nanorods acts as potent and shows enhanced antimicrobial agent against pathogenic fungi, Candida albicans and bacteria, Escherichia coli.
\end{abstract}

\section{Introduction}

During the past two decades, a large quantity of heavy metals and toxic organic pollutants such as synthetic dyes, pesticides, fertilizers, hydrocarbons, phenols, biphenyls, plasticizers, detergents and oils etc have been released into an aquatic environment, from industrial effluents, agriculture waste water, municipal waste water and other environmental changes [1, 2]. Especially, bioaccumulated organic pollutants show potential adverse impact on human as well aquatic life. Among all organic pollutants, carcinogenic and toxic nitrobenzene (NB) has been a great threat to human health. Moreover, NB is stable and resistant to biological or chemical oxidation due to the presence of strong electron affinity nitro group of NB [3]. Therefore it is highly desirable to remove or degrade highly toxic organic pollutants from contaminated water.

There were number of traditional water treatment methods including physical, chemical and biological techniques such as adsorption, coagulation and membrane separation have been developed for removal of dyes from water. However, all these techniques suffer from high operating costs and generate secondary pollutants [4]. More recently, semiconductor heterogenous photocatalysis have emerged as an alternative potential tool for reduction of organic pollutant without generation of any secondary pollutants. Especially, semiconductor photocatalysts such as $\mathrm{TiO}_{2}, \mathrm{ZnO}, \mathrm{Fe}_{2} \mathrm{O}_{3}, \mathrm{CdS}, \mathrm{GaP}, \mathrm{ZnS}$ and $\mathrm{CuO}$ [5-9] have been extensively used for degradation of wide range of organic dye pollutants. Among heterogenous semiconductor photocatalysts, $\mathrm{CuO}$ have been received a special attention for catalytic degradation of organic dye pollutant under visible light radiation due to its non-toxicity, ease of preparation, its unique physical, optical and electrical properties and tunable narrow bandgap (2.1 eV) [10].

Numerous methods have been reported for preparation of $\mathrm{CuO}$ nanostructures such as precipitation, thermal oxidation and combustion [11]. However, all these methods used toxic chemical and thus limits $\mathrm{CuO}$ applications in pollution abatement and biomedical applications. More recently, sonochemical method has been proven as versatile and green route to synthesize the wide range of materials such as metal, oxide,

*Corresponding Author:klbasu@gmail.com(K.Basavaiah) 
(XRD) was recorded using $\mathrm{Cu} \mathrm{K} \alpha$ radiation at $30.0 \mathrm{kV}$ and $30.0 \mathrm{~mA}$ over the scan range $2 \theta, 10-80^{\circ}$ at scan rate of $2^{\circ} \mathrm{min}^{-1}$. Morphology of CuO Nanorods was investigated by field emission scanning electron microscopy (FESEM, JSM-6610LV, Jeol Asia PTE Ltd, Japan) and the elemental analysis was conducted by EDX.

\subsection{Photocatalytic Degradation of NB}

Photocatalytic activity of $\mathrm{CuO}$ nanorods was evaluated in terms of degradation of $\mathrm{NB}$ under visible light. In typical, $50 \mathrm{mg}$ of $\mathrm{CuO}$ was added to $100 \mathrm{~mL} \mathrm{NB}$ aqueous solution (15 mg/L) and then the solution was stirred for 30 minutes in dark to ensure adsorption-desorption equilibrium between $\mathrm{CuO}$ nanorods and $\mathrm{NB}$. The solution was then exposed to $400 \mathrm{~W}$ metal halide lamp and then samples $(5 \mathrm{~mL})$ were collected from the reaction vessel and centrifuged at $2000 \mathrm{rpm}$ for $30 \mathrm{~min}$ to recover the photocatalyst. Photocatalytic experiments were conducted in photoreactor system in presence of visible light source and $20 \mathrm{~cm}$ distance maintained between light source and reaction vessel. The reaction vessel is surrounded with water system to keep the photocatalytic reaction system at ambient temperatures and to absorb the IR radiation.

The percentage of degradation of dye in presence of $\mathrm{CuO}$ was investigated by a UNICAM UV 500, UV-visible spectrophotometer (Thermo Electron Corporation, India). Photodegradation efficiency was reported by plotting $\mathrm{C} / \mathrm{C}_{0}$ vs irradiation time (min), where $\mathrm{C}_{0}$ and $\mathrm{C}$ are the $\mathrm{NB}$ dye concentrations at zero time and time ' $\mathrm{t}$ ' respectively. The value of $\mathrm{C} / \mathrm{C}_{0}$ was taken as the ratio $\mathrm{A} / \mathrm{A}_{0}$, i.e. the absorbance of the solution at $\lambda_{\max }$ at time $\mathrm{t}$ divided by the absorbance at time zero (for NB $\lambda_{\max }=280 \mathrm{~nm}$ ).

$$
\text { Photodegradation } \%=\stackrel{\underline{C}_{0}-C_{t}}{C_{0}} \times 100
$$

where $\mathrm{C}_{0}$ and $\mathrm{C}_{\mathrm{t}}$ corresponds to the initial absorbance and absorbance at time't' respectively.

\subsection{Investigation of Antimicrobial Activity}

The antimicrobial activity was carried out by employing $24 \mathrm{~h}$ young cultures with the given compounds by using agar well diffusion method. The medium was sterilized by autoclaving at $120^{\circ} \mathrm{C}\left(15 \mathrm{lb} / \mathrm{in}^{2}\right)$. About 20 $\mathrm{mL}$ of the medium (Nutrient Agar Medium) with the respective bacterial strains of bacteria and medium (potato dextrose agar) for fungal strains were transferred aseptically into each sterilized Petri plate. The plates were allowed to cool at room temperature for solidification. Each plate was made into 5 wells with equal distance of $6 \mathrm{~mm}$ sterile borer. The test $\mathrm{CuO}$ nanorods were freshly reconstituted in dimethylsulfoxide (DMSO) and tested at various concentrations. The samples and the control along with standard (Ciprofloxacin) were places in 6-mm diameter well. In Antimicrobial assays plates were incubated at $28 \pm 2{ }^{\circ} \mathrm{C}$ for fungi about 24 $\mathrm{h}$ and $37 \pm 2{ }^{\circ} \mathrm{C}$ for bacteria $12 \mathrm{~h}$. Standard with $5 \mu \mathrm{g} / \mathrm{mL}$ was used as a positive control for antibacterial activity. Activity diameter of the zone of inhibition was measured using antibiotic zone scale.

\section{Results and Discussion}

\subsection{UV-Vis Diffuse Reflectance Spectroscopy (UV-Vis/DRS)}

The UV-Vis/DRS spectrum of CuO nanorods is depicted in Fig. 1(a). The band gap of $\mathrm{CuO}$ nanorods was calculated from diffuse reflectance spectra by using Eq.(1),

$$
\mathrm{E}_{\mathrm{g}}=\mathrm{hv}=\mathrm{hc} / \lambda=1240 / \lambda
$$

where $E_{g}$ is bandgap energy, $h$ is planks constant, $v$ is wave frequency, $c$ is light of speed and $\lambda$ is the wavelength. The band gap of $\mathrm{CuO}$ nanorods found to be $2.06 \mathrm{eV}$, which is fall in the visible region of solar spectrum and therefore $\mathrm{CuO}$ nanorods could be utilized as an efficient photocatalyst in visible region of solar spectrum.

\subsection{X-Ray Diffraction Patterns (XRD)}

The XRD patterns of $\mathrm{CuO}$ nanorods were presented in Fig. 1(b).The diffractions peaks centered at $32.67^{\circ}, 35.71^{\circ}, 38.88^{\circ}, 49.01^{\circ}, 53.45^{\circ}$, $58.41^{\circ}, 61.69^{\circ}, 66.35^{\circ}, 68.28^{\circ}, 72.29^{\circ}$ and $75.23^{\circ}$, which are assigned to be (110), (111), (111), (202), (020), (202), (113), (310), (220), (221) and (222) plane of $\mathrm{CuO}$ nanorods. The XRD patterns of $\mathrm{CuO}$ nanorods well in arrangement with the standard JCPDS file (No.96-410-5686) [17]. The average crystallite size of prepared $\mathrm{CuO}$ nanorods was calculated by Debye-Scherrer's equation and found to be $27.62 \mathrm{~nm}$.
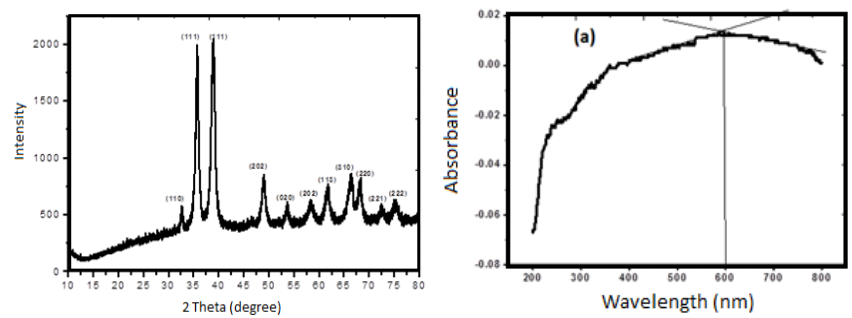

Fig. 1 (a) UV-Vis diffuse reflectance spectra and (b) The powder XRD patterns of $\mathrm{CuO}$ nanorods

\subsection{FTIR Spectroscopy}

FTIR spectrum of $\mathrm{CuO}$ nanorods was depicted in Fig. 2, which is well in agreement with the reported literature. The characteristic bands at 605 and $668 \mathrm{~cm}^{-1}$ ascribed to $\mathrm{Cu}(\mathrm{II})-0$ stretching frequencies respectively [18] There is sharp peak observed at $605 \mathrm{~cm}^{-1}$ in the spectrum is due to characteristics of $\mathrm{Cu}-\mathrm{O}$ bond formation in $\mathrm{CuO}$. The broad absorption band at around $3427 \mathrm{~cm}^{-1}$ is caused by the adsorbed water molecules. Three intense bands were centered at $1384.34 \mathrm{~cm}^{-1}, 1028.92 \mathrm{~cm}^{-1}$ and 1545.73 $\mathrm{cm}^{-1}$ are attributed to the stretching vibrations of $\mathrm{C}=\mathrm{O}, \mathrm{C}=\mathrm{C}$ and $\mathrm{C}-\mathrm{H}$ groups respectively, which suggests its presents as absorbed species in the surface of nanorods [19].

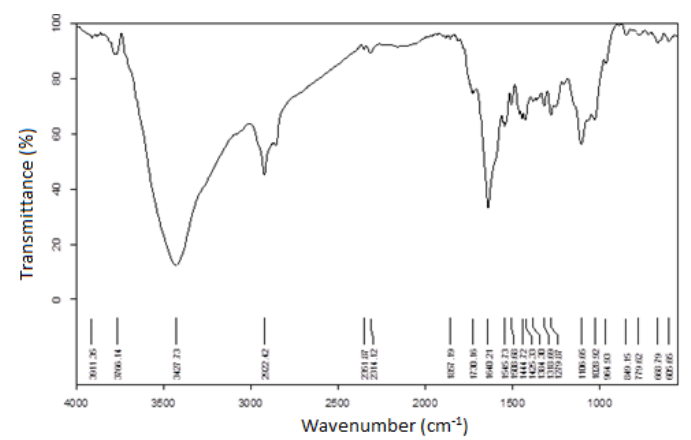

Fig. 2 FT-IR spectra of $\mathrm{CuO}$ nanorods

\subsection{Morphology}

The morphology of as prepared $\mathrm{CuO}$ nanorods was investigated by FESEM. The representative FESEM images and EDX spectrum of CuO nanorods was presented in Fig. 3. FESEM images clearly show the rod like structure. The presence of elemental copper $(\mathrm{Cu})$ and oxygen $(\mathrm{O})$ in the EDX spectrum confirms the formation of $\mathrm{CuO}$ nanorods via sonochemical method. The synthesized $\mathrm{CuO}$ are nearly rod-like structure with average diameter ranges from $18-30 \mathrm{~nm}$.
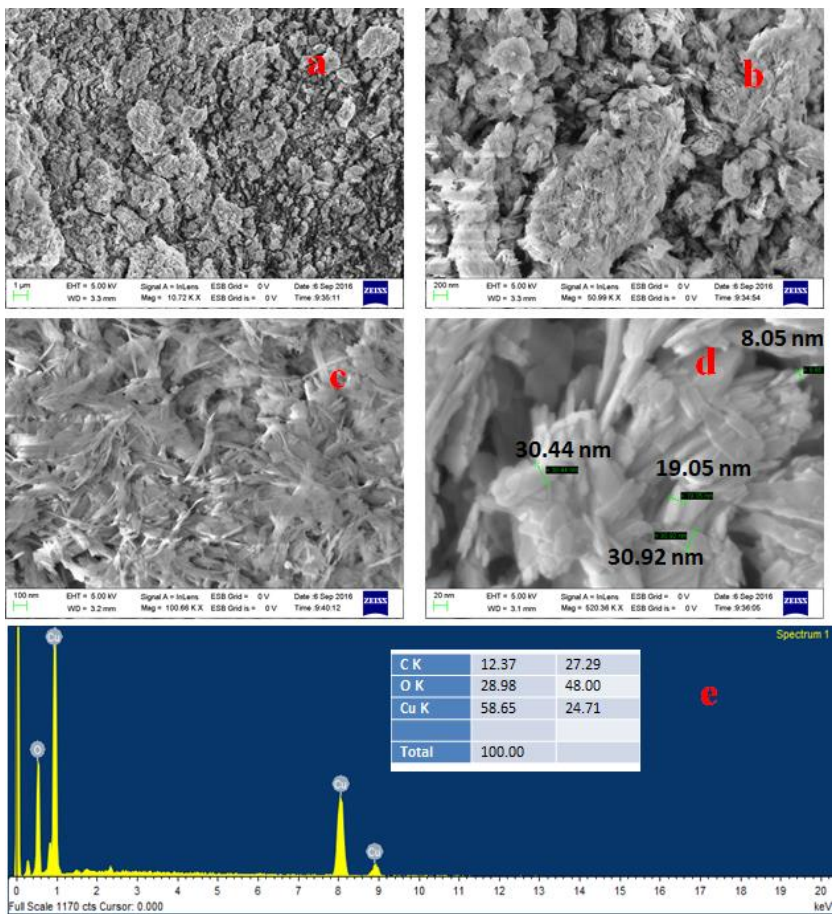

Fig. 3 (a-d) FESEM images and (e) EDX spectrum of CuO nanorods 


\subsection{Raman Analysis}

The Raman spectrum of prepared CuO NPs is presented in Fig. 4. The spectrum shows characteristic Raman bands at 290, 336 and $302 \mathrm{~cm}^{-1}$ [2022] which are in good agreement with reported literature for metal oxides such as $\mathrm{CuO}$.

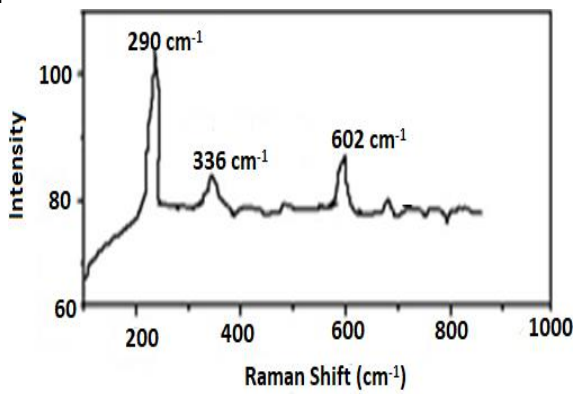

Fig. 4 Raman spectrum of prepared $\mathrm{CuO}$ nanorods

\subsection{Photocatalytic Degradation of NB using CuO Nanorods}

In presence of $\mathrm{CuO}$ nanorods, NB was successfully photodegraded under visible light irradiation. In general, photocatalytic degradation of NB is depended on various experimental conditions such as catalyst dose, $\mathrm{pH}$ of reaction medium and NB concentration. In order to know the best degradation conditions; the degradation was carried out at different experiments. Initially, NB was subjected to visible light radiation for 150 minutes and NB was not degraded under visible light irradiation. There was a significant degradation of $\mathrm{NB}$ in presence of $\mathrm{CuO}$ nanorods as photocatalyst, which is further confirmed by calculating the normalized change in the concentration of NB before and after light irradiation $\left(C / C_{0}\right)$.
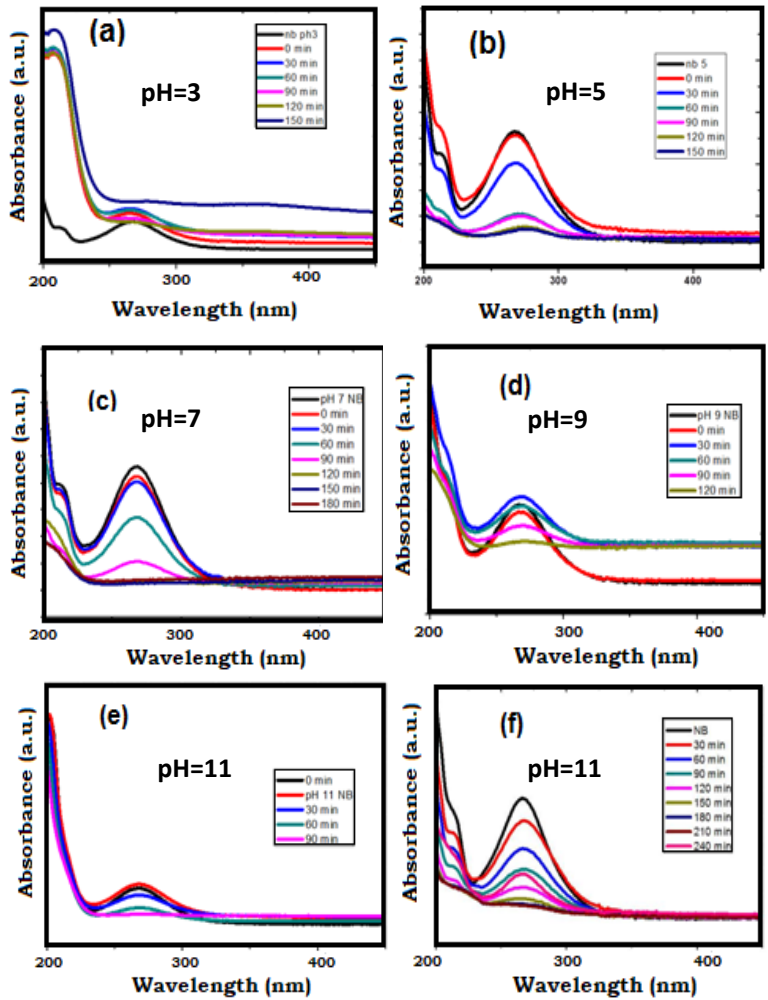

Fig. 5 Photocatalytic activity of $\mathrm{CuO}$ towards the degradation of NB under visible light irradiation at (a-e) different $\mathrm{pH}$ and (f) Only NB

\subsubsection{Effect of $p H$ on Degradation of $N B$}

The surface of $\mathrm{CuO}$ is critically depending on $\mathrm{pH}$ of reaction medium. The point of zero charge $\left(\mathrm{P}_{\mathrm{zc}}\right)$ for $\mathrm{CuO}$ particles is 6.8 , so there is an electrostatic absorption between positive charge surfaces of $\mathrm{CuO}$ and the dye. As the $\mathrm{pH}$ of the system increases, the number of surfaces with negative charge increases on surface of $\mathrm{CuO}$. The effect of variation of $\mathrm{pH}$ of reaction system on photocatalytic degradation was evaluated at constant NB concentration ( $15 \mathrm{mg} / \mathrm{L}$ ) by varying the $\mathrm{pH}$ from $3,5,7,9$ and 11. The degradation efficiencies of NB follows the order $\mathrm{pH}=7>\mathrm{pH}=5>\mathrm{pH}$ $=11 \approx \mathrm{pH}=9>\mathrm{pH}=3$ with percentages of dye degradation are $94.5,89,74$, 51 and $23 \%$ respectively (Fig. 5). The highest photocatalytic degradation of $\mathrm{NB}$ by $\mathrm{CuO}$ nanorods was observed at $\mathrm{pH}=7$ with a degradation efficiency of $94.5 \%$.

https://doi.org/10.30799/jnst.146.18040502

\subsubsection{Effect of Catalyst Dose on Degradation of NB}

The amount of catalyst dose is critically influence the photocatalytic degradation of NB. In order to investigate the optimum concentrate of $\mathrm{CuO}$, the photocatalysis was carried out at different amounts of $\mathrm{CuO}(10 \mathrm{mg}, 20$ $\mathrm{mg}$ and $30 \mathrm{mg}$ ) while the concentration $(15 \mathrm{mg} / \mathrm{L})$ of NB solution kept constant at $\mathrm{pH}=7$. The percentage degradation of NB is increased with increase of dose of catalyst up to $30 \mathrm{mg}$ and then degradation rate decreases by increase in dose of $\mathrm{CuO}$ (Fig. 6). Hence the optimized dosage of photocatalyst could be $30 \mathrm{mg}$.
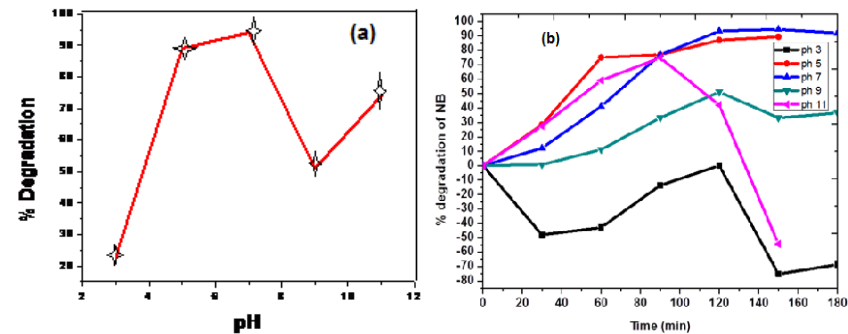

Fig. 6 The percentage of degradation of NB using CuO nanorods (a) under the effect $\mathrm{pH}$ and (b) at different time intervals

The rate kinetic also be calculated from photocatalytic reaction and the calculated values are shown in Table 1, which indicates that entire process follows the pseudo first order reaction. The linear relationship between $\ln \left(\mathrm{C} / \mathrm{C}_{0}\right)$ and time demonstrates that the pseudo first order kinetics shown in Fig. 7.

$$
\mathrm{H}=\ln \left(\mathrm{C} / \mathrm{C}_{0}\right)=\mathrm{kt}
$$

where ' $\mathrm{C} / \mathrm{C}_{0}$ ' is normalized initial concentration, ' $\mathrm{t}$ ' is the reaction time, and ' $\mathrm{k}$ ' is the reaction rate constant $\left(\mathrm{min}^{-1}\right)$.

Table 1 First order kinetic rate constant $(k)$ and regression coefficient $\left(\mathrm{R}^{2}\right)$ of NB degradation under visible light irradiation

\begin{tabular}{lll}
\hline $\mathrm{pH}$ & Nitrobenzene (NB) \\
\cline { 2 - 3 } & $\mathrm{k} \times 10^{-4}{\text { in } \mathrm{min}^{-1}}^{-1}$ & $\mathrm{R}^{2}$ \\
\hline 3 & 1.025 & 0.95 \\
5 & 1.3 & 0.95 \\
7 & 1.66 & 0.98 \\
9 & 2.02 & 0.97 \\
11 & 1.48 & 0.92 \\
\hline
\end{tabular}

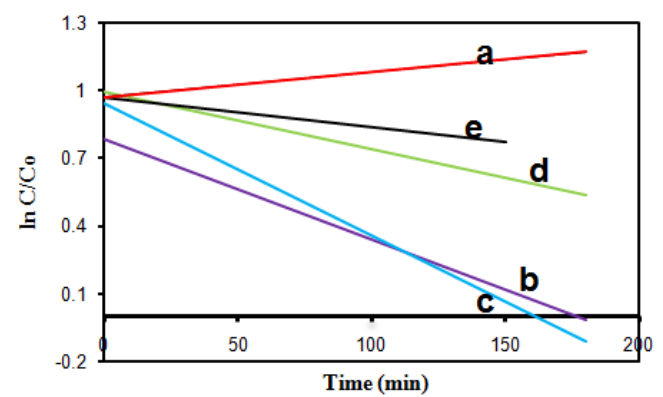

Fig. 7 Plot of $\ln \mathrm{C} / \mathrm{C}_{\mathrm{o}}$ vs time at (a) $\mathrm{pH}=3$, (b) $\mathrm{pH}=5$, (c) $\mathrm{pH}=7$, (d) $\mathrm{pH}=9$, (e) $\mathrm{pH}=11$ and (f) Only NB

\subsection{Antimicrobial Investigation using CuO Nanorods}

The antimicrobial activity of $\mathrm{CuO}$ nanorods was investigated by well diffusion method. The $\mathrm{CuO}$ nanorods showed remarkable antibacterial activity against Gram-negative bacteria, E. coli $(24 \mathrm{~h})$ and antifungal activity against $C$. albicans $(36 \mathrm{~h})$ were shown in Table 2 .

Table 2 Shows Bacteria and fungus organism test by $\mathrm{CuO}$ nanorods

\begin{tabular}{lllll}
\hline $\begin{array}{l}\text { Compound } \\
\text { (Time) }\end{array}$ & Organism/s & $\begin{array}{l}25 \\
\mathrm{mg} / \mathrm{mL}\end{array}$ & $\begin{array}{l}10 \\
\mathrm{mg} / \mathrm{mL}\end{array}$ & $\begin{array}{l}5 \\
\mathrm{mg} / \mathrm{mL}\end{array}$ \\
\hline $12 \mathrm{~h}$ & E.coli & 8 & 8 & - \\
$18 \mathrm{~h}$ & E.coli & 18 & 8 & 8 \\
$26 \mathrm{~h}$ & E.coli & 26 & 12 & 8 \\
$26 \mathrm{~h}$ & C.albicans & 22 & 14 & 7 \\
\hline
\end{tabular}

Fig. 8 shows the results of the inhibition zone values for $\mathrm{CuO}$ against $E$. coli and $C$. albicans. Fig. 9 represents the antibacterial activity achieved 25 $\mathrm{mg} / \mathrm{mL}$ at $24 \mathrm{~h}$ in presence of $\mathrm{CuO}$, shows that the prepared $\mathrm{CuO}$ has potential antibacterial application against E.coli. The antibacterial activity 
of $\mathrm{CuO}$ was mainly attributed to adhesion with bacteria because of their opposite electric charges resulting in a reduction at the bacterial cell wall. Large number of antibiotics carried out by $\mathrm{CuO}$ nanorods owing to their large surface area.
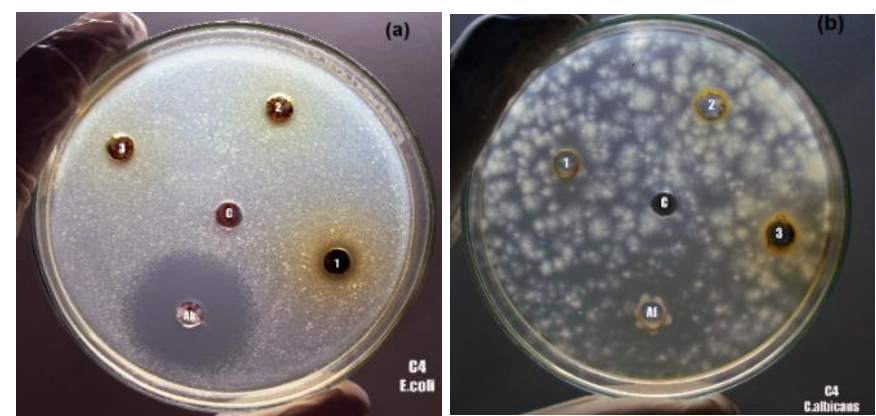

Fig. 8 Photographic images of inhibition zone produced by CuO nanorods against (a) E.coli and (b) C.albicans

Antimicrobial activity of CuO NPs studies is very limited. Among the few studies, $\mathrm{CuO}$ NPs has antibacterial activity against a range of gram-positive and gram-negative bacteria such as $S$. aureus, Epidemic MRSA-15 and $E$. coli [23]. The silver NPs were studied in most related research, exhibiting antibacterial effect at low concentrations [24]. Ionic nanopariculate metal oxides are among the potentially interesting antimicrobial agents, because of their extremely high surface areas and having unusual crystalline structures with high number of edges and corners and other reactive sites [25]. $\mathrm{CuO}$ nanoparticle is the simplest member of the $\mathrm{Cu}$ compounds that reveal a range of potential physical properties and is much cheaper than silver oxide.

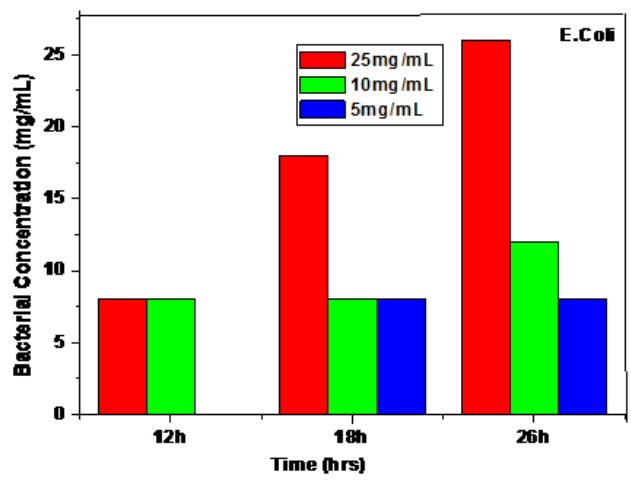

Fig. 9 Representation of bacterial concentration at different time intervals

\section{Conclusion}

In conclusion, $\mathrm{CuO}$ nanorods were successfully synthesised via simple sonochemical route. The spectroscopic and microscopic results reveal the successful formation of $\mathrm{CuO}$ nanorods. The catalytic activity of $\mathrm{CuO}$ nanorods was investigated using model dye, NB under visible light irradiation and shows enhanced degradation of NB in a short time. The prepared $\mathrm{CuO}$ nanorods shows enhanced antimicrobial activity against $E$. coli and fungi C. albicans in $26 \mathrm{~h}$.

\section{Acknowledgement}

B. Sathish Mohan, grateful to University Grants Commission (UGC) for sponsoring Rajiv Gandhi National Fellowship (RGNF-SC-2016-17-AND-
9309). Also, authors thank to UGC-SAP-DRS-I and DST-FIST in Department of Inorganic and Analytical Chemistry, Andhra University.

\section{References}

[1] I. Ali, H.Y. Aboul Enein, Chiral Pollutants: distribution, toxicity and analysis by chromatography and capillary electrophoresis, J. Am. Chem. Soc. 126 (44) (2004) 14680-14680.

[2] Y. Chen, H. Li, W. Liu, Y. Tu, Y. Zhang, W. Han, L. Wang, Electrochemical degradation of nitrobenzene by anodic oxidation on the constructed $\mathrm{TiO}_{2}$ $\mathrm{NTs} / \mathrm{SnO}_{2}-\mathrm{Sb} / \mathrm{PbO}_{2}$ electrode, J. Chemosphere 113 (2014) 48-55.

[3] Z.H. Zhang, Y. Yuan, Y.J. Fang, L.H. Liang, H.C. Ding, L.T. Jin, Preparation of photocatalytic nano- $\mathrm{ZnO} / \mathrm{TiO}_{2}$ film and application for determination of chemical oxygen demand, J. Talanta 73(2007) 523-528.

[4] G. Buddhika, S. Naresh, S. Peter, Degradation of Chlorinated phenols by zero valent iron and bimetals of iron: A review, Environ. Eng. Res. 16 (2011) 187 203.

[5] Y. Zhang, Y.P. Li, H.B. Cao, C.M. Liu, Electrochemical reduction of nitrobenzene at carbon nanotube electrode, J. Hazard. Mater. 148 (2007) 158-163.

[6] A. Vogelpohl, S. Sakthivel, S.U. Geissen, D.W. Bahnemann, V. Murugesan Enhancement of photocatalytic activity by semiconductor heterojunctions: $\alpha$ $\mathrm{Fe}_{2} \mathrm{O}_{3}, \mathrm{WO}_{3}$ and $\mathrm{CdS}$ deposited on $\mathrm{ZnO}$, J. Photochem. Photobiol. A 148 (2002) 283-293.

[7] C. Haneda, X.M. Wang, B.Q. Wang, J.C. Xu, B.X. Zhao, Mai, H.D. Li, Photocatalysis of sprayed nitrogen-containing $\mathrm{Fe}_{2} \mathrm{O}_{3}-\mathrm{ZnO}$ and $\mathrm{WO}_{3}-\mathrm{ZnO}$ composite powders in gas-phase acetaldehyde decomposition, J. Photochem. Photobiol. A 160 (2003) 203-212.

[8] A. Henglein, L. Spanhel, H. Weller, Photochemistry of semiconductor colloids. injection from illuminated CdS into attached $\mathrm{TiO}_{2}$ and $\mathrm{ZnO}$, J. Am. Chem. Soc. 109 (1987) 6632-6635.

[9] J. Rabani, Sandwich colloids of zinc oxide and zinc sulfide in aqueous solutions, J. Phys. Chem. 93 (1989) 7707-7713.

[10] T.P. Radhakrishnan, A. Patra, K. Rajesh, Optical materials based on molecular nano/microcrystals and ultrathin films, Bull. Mater. Sci. 31 (2008) 421-427.

[11] P.S. Subbarao, Y. Aparna, K.V.E. Rao, Proceedings of the $2^{\text {nd }}$ international conference on environment science and biotechnology, IACSIT Press, Singapore, 2012

[12] X.H. Jia, H.Q. Fan, F.Q. Zhang, L. Qin, Using sonochemistry for the fabrication of hollow ZnO microspheres, Ultrason. Sonochem. 17 (2010) 284-287.

[13] V.G. Pol, A. Gedanken, Deposition of gold nanoparticles on silica spheres: A sonochemical approach, J. Chem. Mater. 15(5) (2003) 111-118.

[14] Tao Gao, Taihong Wang, $\mathrm{SnO}_{2}$ nanobelt/CdS nanoparticle core/shell heterostructures are successfully achieved via a simple sonochemical approach, Commun. 22 (2004) 2558-2559.

[15] Qiuying $\mathrm{Li}$, Yulu Ma, Chuang Mao, Chifei Wu, Grafting modification and structural degradation of multi-walled carbon nanotubes under the effect of ultrasonics sonochemistry, Ultrason. Sonochem.16 (2009) 752-757.

[16] K.S. Suslick, M.M. Fang, T. Hyeon, Sonochemical synthesis of iron colloids, J. Am Chem. Soc. 118 (1996) 11960-11961.

[17] S.B. Maddinedi, B.K. Mandal, Peroxidase Like activity of quinic acid stabilized copper oxide nanosheets, Austin J. Anal. Pharm. Chem. 1(2) (2014) 1008-1011.

[18] I. Prakash, P.N. Muralidharan, M. Nallamuthu, Venkateswarlu, N Satyanarayana, Nanocrystallite size cuprous oxide: Characterization of copper nanopowders after natural aging, Mater. Res. Bull. 42 (2007) 1619-1624.

[19] Y.C. Zhang, J.Y. Tang, G.L. Wang, M. Zhang and X.Y. Hu, Tailor the crystal shape in high-temperature solution resulted in a simultaneous growth of $\mathrm{CuO}$ and $\mathrm{Cu}_{2}$ O, J. Cryst. Growth 294 (2006) 278-282.

[20] M. Kosmulski, pH-dependent surface charging and points of zero charge II Update, J. Colloid Interf. Sci. 275 (2004) 214-224.

[21] Sathish Mohan Botsa, Ramadevi Dharmasoth, Keloth Basavaiah, A facile synthesis of $\mathrm{Cu}_{2} \mathrm{O}$ and $\mathrm{CuO}$ nanoparticles via sonochemical assisted method, Curr. Nanosci. 14 (2018) 1-5.

[22] D. Chen, K. Wang, D. Xiang, R. Zong, W. Yao, Y. Zhu, Significantly enhancement of photocatalytic performances via core-shell structure of ZnO@mpg- $\mathrm{C}_{3} \mathrm{~N}_{4}$ Appl. Catal. B Environ. 147 (2014) 554-561.

[23] G. Ren, D. Hu, E.W. Cheng, M.A. Vargas Reus, P. Reip, R.P. Allaker, Characterisation of copper oxide nanoparticles for antimicrobial applications, Int. J. Antimicrobial Agents 33 (2009) 587-590.

[24] P. Cronholm, H.L. Karlsson, J. Hedberg, Intracellular uptake and toxicity of Ag and $\mathrm{CuO}$ nanoparticles: A comparison between nanoparticles and their corresponding metal ions, Small 9 (2013) 970-982.

[25] P.K. Stoimenov, R.L. Klinger, G.L. Marchin, Metal oxide nanoparticles as bacterial agents, Langmuir 18 (2002) 6679-6686. 